\title{
Surgical Outcome of Traumatic Cataract Following Corneal Perforation in Children in a Tertiary Eye Care Centre in Nepal
}

\author{
Shrestha UD ${ }^{1}$, Adhikari $\mathbf{S}^{2}$
}

${ }^{1}$ Dr. Ujjowala Devi Shrestha, MBBS. MD, Consultant Paediatric Ophthalmologist. ${ }^{2} \mathrm{Dr}$. Srijana Adhikari, MBBS. MD, Consultant Paediatric Ophthalmologist. Both from the Tilganga Institute of Ophthalmology, Tilganga, Kathmandu, Nepal.

\section{Address for correspondence:}

Dr. Ujjowala D Shrestha, Associate Professor Consultant Paediatric Ophthalmologist

Tilganga Institute of Ophthalmology

Tilganga, Kathmandu, Nepal

Tel; +977-9849302037

E-mail: ujjowala@gmail.com

Acknowledgements: None

Funding: Nil

Conflict of Interest: None

Permission from IRB: Yes

Ethical dilemmas faced during study: None

\section{How to cite}

Shrestha UD, Adhikari S. Surgical Outcome of Traumatic Cataract Following Corneal Perforation in Children in a Tertiary Eye Care Centre in Nepal. J Nepal Paediatr Soc 2016;36(1):50-55.

doi: http://dx.doi.org/10.3126/jnps.v36i1.14996

This work is licensed under a Creative Commons Attribution 3.0 License.

\section{(c) (i)}

\begin{abstract}
Introduction: Traumatic paediatric cataract is challenging and its management is difficult. It is associated with other distortion of ocular anatomy and subsequent post- operative complication poses more problems. It is mostly unilateral. The purpose of this study is to assess the outcome of traumatic cataract following corneal perforation in Nepalese children in a tertiary eye hospital in Nepal. Material and Methods: It was a retrospective review of medical records of children who developed cataract following perforating corneal injuries. The study included 69 cases diagnosed as unilateral traumatic cataract over a period of 70 months (January 2010 till October 2015) at Tilganga Institute of Ophthalmology (TIO). Traumatic cataracts caused by other than the perforating corneal injuries were excluded from the study. Results: Children between 6 to 10 years of age had highest percentage of ocular trauma. Boys were more commonly affected than girls. Forty two percentages of children had visual outcome of better than or equal to 6/18.Poor visual outcome was mainly due to anterior segment pathology- corneal scar (14.49\%).Posterior segment pathology like macular scar, vitreous haemorrhage and retinal detachment contributed to $7.34 \%$ of the cause. Conclusion: Outcome of the traumatic cataract surgery varied. Visual outcome of post traumatic cataract after corneal perforation was dependent on multiple factors like co- existence of the anterior and posterior segment trauma, per -operative and post-operative challenges. Prompt and good management of traumatic cataract can result in good visual outcome.
\end{abstract}

Key words: Intra-ocular lens (IOL), Traumatic cataract, Traumatic cataract Surgery

\section{Introduction}

$\mathrm{T}$ raumatic pediatric cataract is challenging and its management is more difficult. It is mostly unilateral. It is associated with other distortion of ocular anatomy and subsequent post- operative complication poses more problems. It is one of the causes of the unilateral blindness due to lack of awareness in the community. 
Bow and arrow injury caused the maximum cases of traumatic cataract in different studies. Incidence of traumatic cataract in children is reported as high as $29 \%$ of all childhood cataracts. It causes additional burden to the eye health care system of country ${ }^{1-3}$. The prompt and good management of traumatic cataract by pediatric ophthalmologist can result in good visual outcome ${ }^{4,5,6}$.

The aim of this study was to assess the outcome of traumatic cataract following corneal perforation in Nepalese children at TIO, Nepal.

\section{Material and Method}

It is the retrospective hospital based study. The study includes 69 cases diagnosed as unilateral traumatic cataract over a period of 70 months (January 2010-October 2015) at TIO following corneal perforation. Cause and type of trauma, demographic factors, surgical intervention, complications, and visual acuity were recorded. Those cases which developed the cataract apart from corneal perforation were excluded from the study. The details were obtained from the operation register and outpatient department (OPD). Best corrected preoperative and post operative visual acuity, intra operative, and postoperative complications were analyzed for all eyes. Children attended TIO either in emergency or OPD. All the children had a full ocular examination performed by two paediatric ophthalmologists.

Visual acuity was recorded in all the children. All the children were examined on the slit lamp microscope and by direct and indirect ophthalmoscopy after pupil dilatation as per need of the case. In preverbal children anterior segment examination was done by the hand held slit lamp. B scan ultrasound was done in children to rule out the posterior segment pathology.

Surgical technique: All the surgery was performed under general anaesthesia by two paediatric ophthalmologists 4-6 weeks after the corneal perforation repair $^{7,8}$. Intra-ocular lens (IOL) power calculations were done under general anesthesia. Management of the traumatic cataract was lens aspiration with or without anterior vitrectomy, and with or without intra-ocular lens (IOL) implantation. Anterior vitrectomy was done in all children below 8 years of age. Children were left aphakic if the posterior capsule support was insufficient due to trauma.

\section{Results}

Total of 69 cases underwent the traumatic cataract surgery in 70 months time period. Children between 6 to 10 years of age had highest percentage of trauma than the other two groups (Table 1).

Majority of the patients (94\%) had pre-operative visual acuity of less $3 / 60$ (Table 2 ).

Out of the 69 children, nine patients were advised to follow up in the nearest eye hospital immediately after the surgery. Forty two percentages of children had good visual outcome of better than or equal to $6 / 18$. Fourteen percent of children had poor vision of less than $3 / 60$.

Perforating corneal injuries were the cause of corneal trauma and subsequent traumatic cataract (Table 3). In this study, $43 \%$ of the children developed corneal perforation and traumatic cataract, due to wooden and vegetative material. Only one child with a history of fall from height developed corneal trauma and subsequent traumatic cataracts. Rest of the traumatic cataract was invariably due direct perforating injuries

In this series $5(7.24 \%)$ cases had ruptured anterior capsule. Only one case $(1.44 \%)$ had pre-existing posterior capsular tear. Regarding the type of cataract, $61(88.4 \%)$ was total cataract. Posterior sub capsular cataract was present in two cases $(2.89 \%)$; one was subluxated $(1.44 \%)$.

In this study $82 \%$ of the children with traumatic cataract, underwent IOL implantation (Table 4).

Out of those, only $2.89 \%$ of the cases had pupillary capture in Poly methyl methacrylate (PMMA) intraocular lens ( IOL).

The visual outcome of the traumatic cataract was affected by trauma and various post-operative factors (Table 5 and 6). One child (1.44\%) underwent the dialling of superiorly displaced PMMA IOL. Visual axis opacification (VAO) developed in $8.69 \%$ of the children. Out of those, YAG laser was done in $7.24 \%$ of the children.

Table 1: Age of the children with traumatic cataract

\begin{tabular}{cccl}
\hline Age & Number & Percentage & \\
\hline 0- 5 years & 16 & $23.18 \%$ & \\
\hline 6- 10 years & 37 & $53.62 \%$ & $p>0.05$ \\
\hline 11 to 15 years & 16 & $23.18 \%$ & \\
\hline Total & $\mathbf{6 9}$ & $\mathbf{1 0 0 \%}$ & \\
\hline
\end{tabular}


Table 2: Pre -operative Visual acuity of the children undergoing the traumatic cataract surgery

\begin{tabular}{lcc}
\hline & $\begin{array}{c}\text { Number } \\
(\mathbf{n = 6 9 )}\end{array}$ & $\begin{array}{c}\text { Percentage } \\
(\%)\end{array}$ \\
\hline No perception of light ( NPL) & 1 & $1.44 \%$ \\
\hline $\begin{array}{l}\text { Perception of light(PL) and } \\
\text { Hand movement (HM) }\end{array}$ & 52 & $75.36 \%$ \\
\hline$<3 / 60$ & 12 & $17.39 \%$ \\
\hline $6 / 36$ & 2 & $2.89 \%$ \\
\hline $6 / 24$ & 2 & $2.89 \%$ \\
\hline
\end{tabular}

Table 3: Showing Cause of perforating corneal injury

\begin{tabular}{lcc}
\hline & $\begin{array}{c}\text { Number } \\
\text { (n=69) }\end{array}$ & $\begin{array}{c}\text { Percentage } \\
\text { (\%) }\end{array}$ \\
\hline Wooden stick & 19 & $27.53 \%$ \\
\hline Bamboo & 3 & $4.34 \%$ \\
\hline Thorn & 5 & $7.24 \%$ \\
\hline Vegetative material : & 3 & $4.34 \%$ \\
Pumpkin stump & 1 & $1.44 \%$ \\
\hline Khukuri & 5 & $7.24 \%$ \\
\hline Needle & 2 & $2.89 \%$ \\
\hline Arrow & 4 & $5.79 \%$ \\
\hline Metal piece & 6 & $8.69 \%$ \\
\hline Pencil & 1 & $1.44 \%$ \\
\hline Catapult & 2 & $2.89 \%$ \\
\hline Stone & 1 & $1.44 \%$ \\
\hline Steel & 1 & $1.44 \%$ \\
\hline Rubber & 1 & $1.44 \%$ \\
\hline Ball & 1 & $1.44 \%$ \\
\hline Hand & 1 & $1.44 \%$ \\
\hline Fire cracker & 1 & $1.44 \%$ \\
\hline Buffalo's horn & 11 & $1.44 \%$ \\
\hline Fall from height & $15.94 \%$ \\
\hline Unknown & $100 \%$ \\
\hline Total & 1 & \\
\hline
\end{tabular}

\section{Discussion}

In this study, $42 \%$ of children had good visual outcome of better than or equal to 6/18. Boys were more commonly affected than girls due to the outdoor activities. This finding is consistent with other studies from India and $\mathrm{Nepal}^{9,10,11}$. In this study, $82 \%$ of the children underwent IOL implantation. The less percentage of the pupillary capture may be because of in the bag implantation.

Incidence of VAO in children with traumatic cataract has been reported between $21-100 \%$. The rate of VAO was less $(8.69 \%)$ compared to these reports, probably because anterior vitrectomy was done in all cases. In
Table 4: Primary versus secondary IOL implantation.

\begin{tabular}{lcc}
\hline & Number $(\mathbf{n = 6 9 )}$ & Percentage (\%) \\
\hline Aphakic & 12 & $17.39 \%$ \\
\hline Foldable IOL & 17 & $24.63 \%$ \\
\hline PMMA & 34 & $49.27 \%$ \\
\hline Secondary IOL & 6 & $8.69 \%$ \\
\hline Total & $\mathbf{6 9}$ & $\mathbf{1 0 0 \%}$ \\
\hline
\end{tabular}

Table 5: Squeal of corneal perforating injury

\begin{tabular}{lcc}
\hline & $\begin{array}{c}\text { Number } \\
(\mathbf{n = 1 9 )}\end{array}$ & $\begin{array}{c}\text { Percentage } \\
\text { (\%) }\end{array}$ \\
\hline Corneal scar & 10 & $14.49 \%$ \\
\hline Exotropia & 3 & $4.34 \%$ \\
\hline Esotropia & 1 & $1.44 \%$ \\
\hline Macular scar & 1 & $1.44 \%$ \\
\hline Retinal Detachment & 1 & $1.44 \%$ \\
\hline Vitreous Hemorrhage & 2 & $2.89 \%$ \\
\hline $\begin{array}{l}\text { Retinal detachment } \\
\text { and Vitreous }\end{array}$ & 1 & $1.44 \%$ \\
Hemorrhage & & \\
\hline
\end{tabular}

Table 6: Post- operative complications of traumatic cataract surgery

\begin{tabular}{lcc}
\hline & $\begin{array}{c}\text { Number } \\
(\mathbf{n = 1 4 )}\end{array}$ & $\begin{array}{c}\text { Percentage } \\
\text { (\%) }\end{array}$ \\
\hline Visual axis opacification & 6 & $8.69 \%$ \\
\hline Membrane over the IOL & 2 & $2.89 \%$ \\
\hline Pupillary capture & 2 & $2.89 \%$ \\
\hline $\begin{array}{l}\text { Reposition of superiorly } \\
\text { displaced IOL }\end{array}$ & 1 & $1.44 \%$ \\
\hline Glaucoma & 1 & $1.44 \%$ \\
\hline Endophthalmitis & 2 & $2.89 \%$ \\
\hline
\end{tabular}

cooperative children (7.24\%) who developed VAO, YAG capsulotomy was done. None of the children needed membranectomy.

None of the children developed uveitis in this study. The rate of the endophthalmitis was $2.89 \%$. One of the child developed traumatic endophthalmitis, nine days after the lens aspiration, anterior vitrectomy and PMMA IOL. This child had history of trauma with pencil.

Another child had delayed onset endophthalmitis, five months after the lens aspiration and IOL implantation. This child had history of trauma with bamboo. There was no growth in the vitreous and aqueous tap. This child had VA of $6 / 6$. 
Age and gender of child: The earlier the management of children, the better is the outcome. Stimulation deprivation amblyopia can be prevented by early management. Younger patients respond well to treatment. In some studies very young children had poorer outcome. In other studies, age was not a significant variable affecting visual acuity. Majority of children were of the schoolgoing age group ${ }^{9}$.

Causes of perforating injury: Visual acuity did not differ significantly between patients with cataract after the non- perforating and perforating trauma in one of the studies. In a study done in rural community and tribal belt in India and Nepal, injury by wooden sticks and sharp thorns were the most common causes of traumatic cataract. Wooden sticks were used as firewood and many children, were involved in helping their parents in collecting them ${ }^{12}$. Most of the children came from lower socio-economic background. They were more involved in agricultural activities and playing more outdoor sports like cricket ball, toy guns and fire crackers ${ }^{13}$.

Bow and arrow injury caused the maximum cases of traumatic cataract; cataract extraction resulted in significant visual improvement; and closed globe injuries tended to have better prognosis in paediatric traumatic cataracts. Postoperative complications included amblyopia (51\%) and visual axis opacification (VAO) $(12 \%)^{14}$. The common modes of injury in the penetrating group were wooden splinters in $30.8 \%$ and bow and arrow in $15.4 \%$. Firecrackers and trauma during play with ball were seen in $34 \%{ }^{15}$.Satisfactory visual outcome can be achieved in children with traumatic cataracts; with no significant difference found among open- and closedglobe injuries in the pediatric age group ${ }^{16}$. Children with corneal trauma due to the sharp objects have good prognoses, probably due to less corneal injury. If traumatic cataracts in children are managed promptly and appropriately, visual outcome is good.

Type of cataract and anterior and posterior capsule state: In the study done in tertiary eye care of Eastern Nepal, $74 \%$ of the eyes had total cataract, $26 \%$ partially absorbed cataract, $26 \%$ had pre-existing posterior capsule defect, $7 \%$ had ruptured anterior capsule ${ }^{17}$. In 87 (76.3\%) eyes, the cataract was total and 27 (23.7\%) had partially absorbed cataracts. Ruptured anterior capsule was evident in $6(5.3 \%)$ and that of posterior capsule in $12(10.5 \%)$ at BP Koirala Institute of Health Sciences between 1998$2001^{18}$.
Anterior segment state: Any anterior segment pathology will directly affect the outcome of the traumatic cataract surgery. Corneal scars, adherent leucoma, change of refractive status results in poor outcome. Corneal scar was present in highest percentage of the cases in this study.

Age and timing of traumatic cataracts surgery is important factor in traumatic cataract. In children to prevent stimulation deprivation amblyopia, surgery is done as soon as possible. The rate of post-operative inflammation, uveitis, pupillary capture and VAO is reduced.

In this study, the children were operated for the traumatic cataract surgery within 4 to 6 weeks after the attendance in the hospital.. The median time interval between injury and presentation to the hospital was only 4 days ${ }^{19,} 20,21$.

Variation in Surgical method: Surgery in traumatic paediatric cataract is difficult. Moreover, traumatic cataract is more challenging. It is recommended that the traumatic cataract surgery should be done in quiet eyes. The normal anatomy of child's eye is distorted. Adherent leucoma or cornel scars causes the hindrance in observation of the cataract, posterior capsule and vitreous. Anterior chamber may be shallow or of irregular depth. Iris prolapse may be associated. Pupil may be irregular, poorly dilating. Spinchterotomy may be necessary. In tough anterior capsule, capsulorrehexis was not possible. Due to adherence of anterior capsule to posterior capsule in partially absorbed cataract, anterior capsulotomy was difficult.

IOL: Primary versus secondary IOL implantation: Implantation of $\mathrm{IOL}$ is commonly practiced in traumatic cataract ${ }^{15}$. Primary $\mathrm{IOL}$ implantation is preferred $^{22}$. Out of those, $49 \%$ of children had PMMA IOL implantation. Secondary IOL implantation (8.69\%) was done, only if the visual acuity improved with the aphakic glasses. Contact lenses and aphakic glasses are other alternative. However, contact lenses are unaffordable in Nepalese economy.

\section{VAO, YAG and Membranectomy:}

Uveitis: In children there is a greater chance of post operative inflammation due to fibrinotic reactions. In $2.89 \%$ of the children, membrane was seen anterior to the IOL. Intense topical and 
oral anti-inflammatory corticosteroid medication was advised. Children have easily disruptable immature blood aqueous barrier and low inherent fibrinolytic activity. It encourages the release of plasma proteins, clotting factors and fibrin into the anterior chamber. This is more so in traumatic cataract $^{23,24,25}$. Severe inflammation and postoperative uveitis is managed by frequent application of topical antibiotic and steroid drops.

Endophthalmitis and intravitreal injection: Post - traumatic endophthalmitis is common in corneal perforation. Unless managed promptly, with intravitreal antibiotic injection the outcome of the traumatic cataract surgery has poor prognoses.

Posterior segment status: Macular pucker, scar, retinal detachment is the other causes of poor visual outcome. Visual acuity $42 \%$ of children had good visual outcome of better than or equal to $6 / 18$. Poor visual outcome was mainly due to anterior segment pathology -corneal scar (14.49\%). Posterior segment pathology like macular scar, vitreous hemorrhage and retinal detachment contributed to $7.34 \%$ of the cause. This is similar to other studies where the cause of poor visual acuity (less than 6/18) in $64.4 \%$ of the subjects included cornea opacity $12.5 \%$, posterior capsule opacification $12.5 \%$, retinal detachment $9.4 \%$, and glaucoma $6.9 \%$. Because, it is not only the lens which decides prognosis, different types of management are done in different post-operative outcome ${ }^{26},{ }^{27}$, Gradin et al. reported that $64.7 \%$ had vision better than $20 / 60$ after surgery

\section{References}

1. Panda A, Bhatia IM, Dayal Y. Ocular injury - a socioeconomic importance. Afro Asian Ophthalmol 1985; 3: 172-4.

2. Mundada R, Shinde S, Pathan MS, Badaam KM. Traumatic Cataract Epidemiology at Tertiary Care Hospitalin Aurangabad Maharashtra India: An Observational Study: Int $J$ recent trends in Sci and Technol 2014;9(3);403-405

3. Eckstein M, Vijayalakshmi P, Killedar M, Gilbert C, Foster A. Aetiology of childhood cataract in South India. Br J Ophthalmol 1996;80:628-32.

4. Zetterström C. Intraocular lens implantation in the pediatric eye. J Cataract Refract Surg. 1997;23:559600.

5. Metge P, Cohen H, Chemila JF. Intracapsular implantation in children. Eur J Implant Refract Surg 1990;2:319-23 for traumatic cataract. Aldakaf et al. and Sternberg et al. reported that initial vision and mechanism of injury were predictors of final outcome. Evaluation of visual outcome in traumatic cataract and adult cataract are similar, but the co-morbidity, causes the difference in success rates ${ }^{28}$. This statement is true for traumatic cataract in children.

\section{Conclusion}

Outcome of the traumatic cataract surgery varied. Visual outcome of post traumatic cataract after corneal perforation is dependent on multiple factors like co-existence of the anterior and posterior segment pathology, per- operative and post-operative challenges. Forty two percentages of children had good visual outcome of better than or equal to $6 / 18$.

Prompt and good management of traumatic cataract can result in good visual outcome. Poor visual outcome was mainly due to anterior segment pathology -corneal scar (14.49\%).

\section{Recommendation}

Awareness among the parents and community about the hazards should be created. In addition to that, community should be informed that in any ocular injury, children should be taken to nearest eye hospital. Regular post operative follow up of children should be encouraged for the management of traumatic cataract. The prompt and good management of traumatic cataract can result in good visual outcome.

6. Wilson ME, Peterseim MW, Englert JA, Lall-Trail JK, Elliott LA. Pseudophakia and polypseudophakia in the first year of life. J AAPOS. 2001; 5: 238-45.

7. Brar GS, Ram J, Pandav SS, Reddy GS, Singh U, Gupta A. Postoperative complications and visual results in uniocular pediatric traumatic cataract. Ophthalmic Surg Lasers. 2001; 32:233-8.

8. XuYN, HuangYS, XieLX. Pediatric traumatic cataract and surgery outcomes in eastern China: a hospital -based study. International Journal of Ophthalmology 2013; 6(2):160-164.

9. Gogate P, Sahasrabudhe M, Shah M, Patil S, Kulkarni A. Causes, epidemiology, and long-term outcome of traumatic cataracts in children in rural India. Indian J Ophthalmol 2012;60:481-6

10. Reddy AK, Ray R, Yen YG. Surgical intervention of traumatic cataracts in children: Epidemiology, complications and outcomes. J AAPOS 2009;13:1704. 
11. Adlina AR, Chong YJ, Shatriah I. Clinical profile and visual outcome of traumatic paediatric cataract in suburban Malaysia: a tenyearexperience. Sing Med J.2014;55(5):253-6

12. Khatry SK, Lewis AE, Schein OD, Thapa MD, Pradhan $\mathrm{EK}, \mathrm{Katz} \mathrm{J}$, et al. The epidemiology of ocular trauma in rural Nepal. Br J Ophthalmol 2004;88:456-60.

13. Witsaman RJ, Comstock RD, Smith GA. Pediatric firework related injuries in the United Sates 1990-3. Pediatrics 2006;118(1):296-303

14. Khokar S, Gupta S, Yogi R, Gogia V, Agrawal T. Epidemiology and intermediate -term outcomes of open and closed globe injuries in traumatic childhood cataract. Eur J Ophthalmol 2014;24(1):124-30

15. Ram J, Verma N, Gupta N, Chaudhary M. Effect of penetrating and blunt ocular trauma on the outcome of traumatic cataract in children in northern India. $J$ Trauma Acute Care Surg 2012;73(3):726-30

16. Shah MA, Shah SM, Appleware AH, Patel KD, Rehman RM, Shikhange KA. Visual outcome of traumatic cataract in pediatric age group. Eur $J$ Ophthalmol 2012;22(6):956 - 63.

17. Panda A, Kumar S, Das H, Badhu BP. Striving for the Perfect Surgery in Traumatic Cataract following Penetrating Trauma in a Tertiary Care Hospital at Eastern Nepal J Nepal Med Assoc 2007;46(167):11925

18. Kumar S, Panda A, Badhu BP, Das H Safety of Primary Intraocular lens Insertion in Unilateral Childhood traumatic cataract. I Nepal Med Assoc 2008;47(172):179-85
19. Gogate P, Khandekar R, Srisimal M, Dole K, Taras S, Kulkarni $\mathrm{S}$, et al. Cataracts with delayed presentationare they worth operating upon? Ophthalmic Epidemiol 2010; 17:25-33.

20. Kuhn F. Traumatic cataract:what, when, how. Graefes Arch Clin Exp Ophthalmol 2010;248:1221-23

21. Rumelt S, Rehany $U$. The influence of surgery and intraocular lens implantation timing on visual outcome in traumatic cataract. Graefes Arch Clin Exp Ophthalmol 2010; 248:1293-97.

22. Shrestha UD Cataract surgery in children: Controversies and practices. Nepal J Ophthalmol 2012;4(7):138-49

23. Angra SK, Ahmed A, Panda A,Vajpayee RB. Role of low molecular weight heparin in paediatric cataract surgery. Visiscan 1996;5:47-54.

24. Bekibele CO, Fasina O. Visual outcome of traumatic cataract surgery in Ibadan, Nigeria. Niger J Clin Pract 2008;11:372-5.

25. Mohammadpour M, Jafarinasab MR, Javadi MA. Outcomes of acute postoperative inflammation after cataract surgery. Eur J Ophthalmol 2007;17:20-8.

26. Bekibele CO, Fasina O.Visual outcome of traumatic cataract surgery in Ibadan, Nigeria. Niger J Clin Pract 2008;11(4):372-5.

27. Shah M, Shah S, Gupta L, Jain A, Mehta R. Predictors of visual outcome in traumatic cataract. World $\mathrm{J}$ Ophthalmol 2014;4(4):152-59.

28. Shah MA, Shah SM, Shah SB, et al. Morphology of traumatic cataract: does it play a role in final visual outcome? BMJ Open 2011;1:e000060. 